\title{
A Study of The Effect Of Understorey Foliage Density On Bat Diversity and Abundance In The Guyana Shield Rainforest
}

\author{
Juliet I. M. Russell \\ Shrewsbury School, The Schools, Shrewsbury, Shropshire, SY3 7AT, England; jetty2001@icloud.com
}

ABSTRACT: This paper aims to look at the effect of understorey foliage density on bat populations, understanding of which may be crucial for conservation of the some 1,400 bat species around the world. ${ }^{1}$ With risks posed to their habitats, such as logging and forest clearing, ${ }^{2}$ understanding their interaction with forest foliage may be vital in protecting these species, as nesting sites and food sources are increasingly threatened by human activity. ${ }^{3}$ Although this study has not been able to show any significant relationship between foliage density and bat abundance, due to lack of data, the use of diversity indices and contingency tables suggests that certain bat species may rely on the presence of particular tree species for roosts and/or food sources. Across two unlogged sites, understorey mist nets were used to catch a total of 221 bats over a two-week period and 'touchpole' data was used as a proxy for foliage density. The results of this study, although inconclusive, suggest that the removal of understorey on bat populations may be greater than previously thought given that bat species dependence on certain tree species is perhaps indicated in this study.

KEYWORDS: Biology, Guyana, Conservation, Bats, Rainforest, Understorey density, Operation Wallacea.

\section{Introduction}

The Guyana Shield is an area of 270 million hectares of rainforest, spanning multiple South American countries. It is believed to be home to 148 species of bat; ${ }^{4}$ only a tiny proportion of over 3,000 vertebrate species ${ }^{5}$ believed to be found in the forest. Not only home to more common species, it offers habitat for numerous endemic species of both plants and animals and, for this reason, the Shield has become a popular region for conservation studies and projects. Operation Wallacea ${ }^{6}$ runs biodiversity and conservation management research expeditions across the world, recording changes in biodiversity and collecting data on a range of different species.

The author took part in a 2019 trip to the Guyana Shield with Operation Wallacea. The aim of this trip was to study and record the different levels of general biodiversity at two sites. These sites were sufficiently far apart (c.4hrs by bus) for their bat populations (the focus of this study) to be viewed as separate and distinct, with approximately the same level of human disturbance: no logging, sustainable or otherwise, was being carried out near either location. The data collected on the bat populations and vegetation has been used in this study to see if there is a correlation between forest understorey foliage density and bat abundance (and diversity). The hypothesis for this study: as density of understorey foliage increases, bat abundance will decrease. In addition, as foliage becomes denser, a different diversity of species may be found, with species adapted to cluttered forest environments found in greater numbers in areas of denser foliage. Bats are constrained by their wing morphology and echolocation call structure to certain types of habitat; ${ }^{7}$ some guilds of bat are adapted for flight in open areas, with long narrow wings, whereas others with short, broad wings are adapted to the more tightly packed foliage of a denser understorey. As density of foliage increases, so does the number of obstacles in a bat's flight path and, although it has been shown that their echolocation systems are so accurate that they can avoid obstacles the width of telephone wires, ${ }^{8}$ the more obstacles present, the greater the chance of a potentially damaging/life threatening collision. Additionally, the more foliage, the more changes of direction are required, inevitably slowing a bat down, leading to a potential loss of prey.

For other animals such as birds, higher density understorey foliage may be beneficial since, although it slows them down, it also provides increased protection from predators, of which many are larger birds, which may struggle to pursue them through denser foliage. The thicker understorey also provides a protective layer through which it becomes harder for predators to see them from above and for many birds such as the humming birds and nectar feeders, the risks of predation, when they are relatively stationary whilst at a flower for example, might outweigh the benefits of a clearer flight path. However, for some species of bat, the risk of not finding food is just as dangerous as that of predation; for example, species of vampire bat, such as Desmodus rotundus, need to feed at least once every 48 hours or so, or they cannot survive. ${ }^{8}$ Due to their nocturnal habits, predation may be expected to be relatively low in comparison to that of small birds, as predators which rely on sight to catch their prey are limited by the low light intensity. Therefore, the most dangerous times for bats tend to be when they leave their roosts at dusk; a time when they are visible to all possible predators. At this point, perhaps a denser understorey may be beneficial, but after that point it may not. Dense foliage will act as an obstruction to echolocating of prey. If an insect is obscured by a leaf, the bat's high frequency, short wavelength emissions of sound would not detect it. The waves of sound 
would bounce back to the bat off the leaf, not reaching the insect and the bat would not, therefore, necessarily be aware of its presence. Bats may suffer from 'clutter' echoes.'

The density of foliage may have different effects on bats depending on species and on what a particular area is used for by the bats (e.g. roosting or feeding). Bats aim to be as efficient as possible in all flying that they do and in order to conserve energy they need to come to a compromise on speed. ${ }^{8}$ As speed increases, two power inputs increase, but one decreases, and so optimum speeds can differ for different activities. When a bat is making a migratory or long flight, they want to fly fast to spend as little time in the air as possible. For this, they will want a clearer flight path without obstructions and deviations. Similarly, when flying from a roost to a foraging site, bats want to get there fast. If they are too late, they might miss the peak time for insects and lose possible foraging time or be in reach of predators for longer. Again, in this instance they might want a clear path to waste less feeding time. However, when feeding, a bat will want to maximise the time for which they can stay out foraging so therefore speed will most probably decrease. Increased density may then be less of a problem as bats will be swerving and diving to catch insects or find other food. Increased foliage density may also offer more places to find food. But, if too dense, foliage will still hinder a bat's progress and affect its echolocation. Therefore, a slightly sparser area of forest might be preferable.

\section{Results and Discussion Bat Data:}

Data collected showed absolute number, different species and locations of bats (see Table 1). The data indicates that the number of bats caught across the two locations did not differ hugely, but that the species diversity and species ratios were significantly different between Turtle Mountain and Rock Landing.

Table 1: Number of bats captured.

\begin{tabular}{|llccc|} 
Date & Net Hours & $\begin{array}{c}\text { \# Bats } \\
\text { captured }\end{array}$ & Bats/Hour & $\begin{array}{c}\text { \# Bats } \\
\text { recaptured }\end{array}$ \\
\hline Turtle Mountain & & & \\
$08 / 07 / 2019$ & 6.50 & 65 & 10.0 & 0 \\
$09 / 07 / 2019$ & 6.00 & 11 & 1.8 & 0 \\
$10 / 07 / 2019$ & 6.00 & 20 & 3.3 & 0 \\
$11 / 07 / 2019$ & 6.00 & 14 & 2.3 & 1 \\
$12 / 07 / 2019$ & 6.50 & 6 & 0.9 & 0 \\
\cline { 2 - 5 } & 31.00 & 116 & 3.7 & 1 \\
\hline
\end{tabular}

\begin{tabular}{|llccc|}
\hline Date & Net Hours & $\begin{array}{c}\text { \# Bats } \\
\text { captured }\end{array}$ & Bats/Hour & $\begin{array}{c}\text { \# Bats } \\
\text { recaptured }\end{array}$ \\
\hline Rock Landing & & & \\
$14 / 07 / 2019$ & 6.00 & 42 & 7.0 & 1 \\
$15 / 07 / 2019$ & 6.00 & 24 & 4.0 & 2 \\
$16 / 07 / 2019$ & 3.50 & 7 & 2.0 & 0 \\
$17 / 07 / 2019$ & 6.00 & 17 & 2.8 & 2 \\
$18 / 07 / 2019$ & 4.50 & 15 & 3.3 & 0 \\
\cline { 2 - 5 } & 26.00 & 105 & 4.0 & 5 \\
\hline
\end{tabular}

Table 2: Bat species data - Turtle Mountain.

\begin{tabular}{|l|c|c|c|c|c|c|}
\hline Species & \multicolumn{7}{c|}{$\begin{array}{l}\text { Location } \\
\text { Turtle Mountain }\end{array}$} \\
\hline DATE & $08 / 07 / 2019$ & $09 / 07 / 2019$ & $10 / 07 / 2019$ & $11 / 07 / 2019$ & $12 / 07 / 2019$ & TOTAL \\
\cline { 2 - 8 } Net Hours & 6.5 & 6.0 & 6.0 & 6.0 & 6.5 & \\
\hline Artibeus gnomus & 1 & - & - & 1 & - & 2 \\
\hline Artibeus lituratus & 4 & - & 2 & 1 & 1 & 8 \\
\hline Artibeus obscurus & 2 & - & - & - & - & 2 \\
\hline Artibeus planirostris & 39 & 11 & 13 & 6 & 3 & 72 \\
\hline Carollia perspicillata & 9 & - & 1 & 2 & 1 & 13 \\
\hline Chiroderma trinitatum & - & - & - & - & - & - \\
\hline Desmodus rotundus & - & - & - & - & - & - \\
\hline Glossophaga soricina & - & - & - & 1 & - & 1 \\
\hline Glyphonycteris daviesi & 1 & - & 1 & - & - & 2 \\
\hline Glyphonycteris sylvestris & - & - & - & - & - & - \\
\hline Lionycteris spurrelli & - & - & - & - & - & - \\
\hline Lophostoma silvicolum & 1 & - & - & - & 1 & 2 \\
\hline Mesophylla macconnelli & - & - & - & - & - & - \\
\hline Micronycteris megalotis & - & - & 1 & - & - & 1 \\
\hline Micronycteris sp. & - & - & - & - & - & - \\
\hline Mimon bennettii & - & - & - & - & - & - \\
\hline Mimon crenulatum & - & - & - & - & - & - \\
\hline Phylloderma stenops & - & - & - & - & - & - \\
\hline Phyllostomus elongatus & 1 & - & - & - & - & 1 \\
\hline Pteronotus parnellii & 5 & - & 1 & 2 & - & 8 \\
\hline Rhinophylla pumilio & 1 & - & 1 & - & - & 2 \\
\hline Tonatia saurophila & - & - & - & - & - & - \\
\hline Trachops cirrhosis & 1 & - & - & - & - & 1 \\
\hline Uroderma bilobatum & - & - & - & 1 & - & 1 \\
\hline Vampyriscus bidens & - & - & - & - & - & - \\
\hline TOTAL & $\mathbf{6 5}$ & $\mathbf{1 1}$ & $\mathbf{2 0}$ & $\mathbf{1 4}$ & $\mathbf{6}$ & $\mathbf{1 1 6}$ \\
\hline
\end{tabular}

Table 3: Bat species data - Rock Landing.

\begin{tabular}{|l|c|c|c|c|c|c|}
\hline Species & \multicolumn{7}{c|}{$\begin{array}{l}\text { Location } \\
\text { Rock Landing }\end{array}$} \\
\hline DATE & $14 / 07 / 2019$ & $15 / 07 / 2019$ & $16 / 07 / 2019$ & $17 / 07 / 2019$ & $18 / 07 / 2019$ & TOTAL \\
\cline { 2 - 8 } Net Hours & 6.0 & 6.0 & 3.5 & 6.0 & 4.5 & \\
\hline Artibeus gnomus & - & 1 & - & - & 1 & 2 \\
\hline Artibeus lituratus & - & - & - & - & 1 & 1 \\
\hline Artibeus obscurus & 7 & 5 & - & 3 & 2 & 17 \\
\hline Artibeus planirostris & 6 & 4 & 2 & 5 & 3 & 20 \\
\hline Carollia perspicillata & 11 & 1 & 1 & 4 & 1 & 18 \\
\hline Chiroderma trinitatum & 1 & - & - & - & - & 1 \\
\hline Desmodus rotundus & - & - & - & - & 1 & 1 \\
\hline Glossophaga soricina & 1 & - & - & - & 1 & 2 \\
\hline Glyphonycteris daviesi & - & - & - & - & - & - \\
\hline Glyphonycteris sylvestris & 1 & - & - & - & - & 1 \\
\hline Lionycteris spurrelli & 1 & - & 1 & - & 1 & 3 \\
\hline Lophostoma silvicolum & 4 & 1 & 1 & 2 & 1 & 9 \\
\hline Mesophylla macconnelli & 1 & - & - & - & - & 1 \\
\hline Micronycteris megalotis & - & - & - & - & - & - \\
\hline Micronycteris sp. & - & 1 & - & - & - & 1 \\
\hline Mimon bennettii & - & - & - & 1 & - & 1 \\
\hline Mimon crenulatum & 1 & 1 & - & - & 2 & 4 \\
\hline Phylloderma stenops & 1 & 1 & - & 1 & - & 3 \\
\hline Phyllostomus elongatus & 2 & - & 1 & 1 & - & 4 \\
\hline Pteronotus parnellii & 1 & 3 & 1 & - & 1 & 6 \\
\hline Rhinophylla pumilio & - & - & - & - & - & - \\
\hline Tonatia saurophila & 1 & - & - & - & - & 1 \\
\hline Trachops cirrhosis & 2 & 4 & - & - & - & 6 \\
\hline Uroderma bilobatum & 1 & - & - & - & - & 1 \\
\hline Vampyriscus bidens & - & 2 & - & - & - & 2 \\
\hline TOTAL & $\mathbf{4 2}$ & $\mathbf{2 4}$ & $\mathbf{7}$ & $\mathbf{1 7}$ & $\mathbf{1 5}$ & $\mathbf{1 0 5}$ \\
\hline
\end{tabular}

Table 4: Total bat numbers at each location over 5 nights.

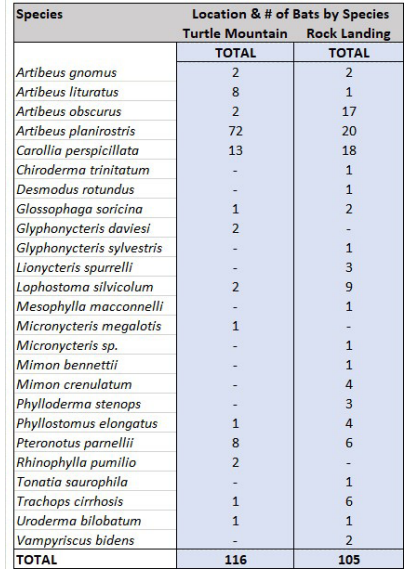


Shannon-Weaver Index of Diversity:

Using the data shown in Table 4, the Shannon-Weaver Index of Diversity has been calculated for each location.

Based on the Shannon index, Rock Landing had a markedly higher bat diversity $(\mathrm{H}=2.528)$ than Turtle Mountain $(\mathrm{H}=$ 1.465).

\section{Simpson's Index of Diversity:}

Also using the data shown in Table 4, the Simpson's Index has been calculated for Turtle Mountain and Rock Lading.

This index produces results between 0 (no diversity: no species) and 1 (infinite diversity: many species all with similar/the same relative abundance)

Based on the Simpson's index, Rock Landing has a higher bat diversity $(\mathrm{D}=0.90)$ than Turtle Mountain $(\mathrm{D}=0.60)$.

\section{Chi-Squared Test:}

Both values exceed the critical value of 7.81 for $p=0.05$ and of 11.34 for $p=0.01$ at 3 degrees of freedom. Therefore the null hypothesis can be confidently rejected; that bat species are independent of their location as there is less than $1 \%$ chance that the difference is down to chance. They are, it seems, dependent, which will be discussed later in the conclusion.

Table 5: Tree species recorded in each location.

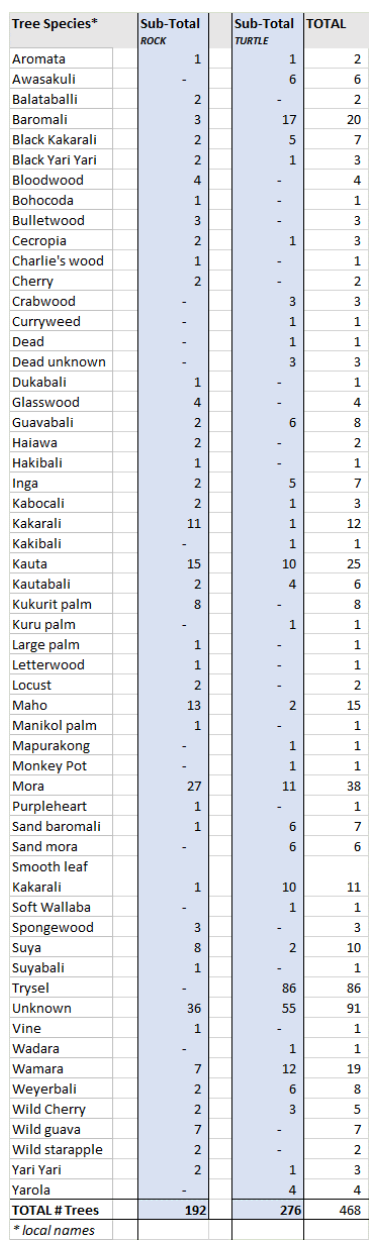

\section{Forestry Data:}

\section{a) Shannon-Weaver}

Using the data from Table 6; Based on the Shannon index the diversity of trees was higher in Rock Landing $(\mathrm{H}=3.368)$ than in Turtle Mountain $(\mathrm{H}=2.561)$, just as it was with the bats.

Table 6: Touchpole measurements.

\begin{tabular}{|c|c|c|c|c|c|c|c|}
\hline Transect & $0.5 \mathrm{~m}$ & $1.0 \mathrm{~m}$ & $1.5 \mathrm{~m}$ & $2.0 \mathrm{~m}$ & $2.5 \mathrm{~m}$ & $3.0 \mathrm{~m}$ & Total Touches \\
\hline \multicolumn{8}{|l|}{ TURIIE } \\
\hline Birds & 5 & 17 & 17 & 14 & 19 & 31 & 103 \\
\hline Birde & 9 & 14 & 16 & n & 29 & 9 & 98 \\
\hline SR3 & 17 & 30 & 27 & 27 & 42 & $\mathbf{2 3}$ & 166 \\
\hline SRA & 26 & 22 & 10 & 33 & 27 & 27 & 185 \\
\hline SR2 & 35 & $\mathbf{8}$ & 18 & 8 & 5 & 4 & 70 \\
\hline BAZ & 12 & 13 & 4 & 2 & 11 & 8 & so \\
\hline BA1 & 11 & 14 & 5 & 17 & 7 & 8 & 62 \\
\hline FS17 & 8 & 18 & 10 & 6 & $\mathbf{1 5}$ & 12 & 69 \\
\hline FS16 & 10 & 13 & $\mathbf{8}$ & 12 & 14 & 23 & 90 \\
\hline FSOI & 11 & 16 & 22 & 28 & 28 & 41 & 138 \\
\hline FSZO & 12 & 16 & 12 & 11 & 19 & $\mathbf{8}$ & 78 \\
\hline \multirow{2}{*}{\multicolumn{8}{|c|}{$\operatorname{ROCX}$}} \\
\hline & & & & & & & \\
\hline Transect & $0.5 \mathrm{~m}$ & $1.0 \mathrm{~m}$ & $1.5 \mathrm{~m}$ & $2.0 \mathrm{~m}$ & $2.5 \mathrm{~m}$ & \multicolumn{2}{|c|}{ 3.0m Total Touches } \\
\hline BA5 & 189 & 34 & 27 & 31 & 37 & 31 & 269 \\
\hline BA6 & 58 & 25 & 6 & 13 & 11 & 13 & 118 \\
\hline FS39N & $\mathbf{8}$ & 7 & 3 & 4 & 19 & $\boldsymbol{n}$ & 63 \\
\hline FSAON & 12 & 11 & 18 & 9 & 22 & 17 & 89 \\
\hline Birdo & 32 & 14 & 9 & 16 & 24 & 34 & 120 \\
\hline Birnts & 12 & 8 & 3 & 6 & $\mathbf{1}$ & 8 & $\mathbf{3 8}$ \\
\hline FSA1 & 36 & 18 & 8 & 15 & 19 & 34 & 130 \\
\hline FS37 & 23 & 12 & 2 & 3 & 7 & 23 & 70 \\
\hline FSA2 & 48 & 15 & 11 & 12 & 25 & 9 & 120 \\
\hline SRR13 & 18 & 24 & 17 & 11 & 13 & 12 & 95 \\
\hline FSZ3N & 36 & 30 & 16 & 17 & 28 & 33 & 160 \\
\hline SRP14 & 35 & 16 & 9 & 6 & 17 & 6 & 89 \\
\hline
\end{tabular}

\section{b) Mann-Whitney UTest:}

Using data from Table 7;

The outcome for $U_{1}=88.5$, and for $U_{2}=43.5$.

The lower of the two $U$ values was then compared to the critical value, at $\mathrm{p}=0.05$, for sample sizes of 11 and 12 . The relevant critical value in this instance is 33 ; this is exceeded by the lowest $U$ value of 43.5 and therefore null hypothesis is accepted. This means that there is no significant difference between the understorey foliage density at the Turtle Mountain and Rock Landing sites. This suggests that the difference between bat diversities should, therefore, be due to another factor.

\section{- Discussion}

\section{Bats:}

The statistical tests on the bat data show that there were differences between the bat assemblages in the two locations. Whilst Turtle Mountain may have had more bats caught over the time the author was there (although the nets were also open for marginally longer due to bad weather conditions at Rock Landing), there were fewer different species than were found at Rock Landing. The diversity indices demonstrate that the two locations are home to not only different species, but different numbers of species.

Whilst the chi-squared test does not indicate the number of bats found in an area, it does demonstrate that the populations are, in some way, dependent on their location. ${ }^{10}$ This test could not consider all the data due to low numbers of certain species, but it may nevertheless be representative of the whole sample. Unfortunately, it cannot indicate any correlation between understorey foliage density and numbers or species of bats.

\section{Forestry:}

Whilst this cannot be statistically shown with only two sets of data, it can be seen that where there is increased tree diversity there is also higher bat diversity and from this it can be inferred that there may be a positive correlation between the two factors. This may be down to chance given the lack 
of sufficient data to form a proper correlation, but it may also be related to niche availability: with a higher tree diversity there is likely to be a wider range of food available to different bat species, opening up more niches for them to fill. A wider range of trees offers a wider range of habitats and food sources to support more different bat species; this might be down to the fruits growing on trees or the insects living in them or the roosts available. The data indicates that different species of bats prefer habitats containing certain tree species. In the Turtle Mountain area, 86 Trysel trees were recorded whilst none were found at Rock Landing and 72 Artibeus planirostris were found at the former and only 20 at the latter. Whilst the data is not sufficient to indicate this statistically, it appears that there may be a correlation between certain tree species and a particular species of bat, either due to roosting or feeding preferences.

The touch pole data did not provide any significant results, with the median values for the data sets from the two sites being fairly similar. More data is required to assess a possible correlation between the bat and forestry data.

\section{- Conclusion}

Unfortunately, due to lack of data, it has not been possible to show any significant link between understorey foliage density and bat population numbers, as, on analysis, although the bat populations and species distribution vary between the two locations, "Turtle Mountain" and "Rock Landing" appear to have similar understorey foliage density, suggesting that this is not the influencing factor in the differences seen between the bat populations. It suggests that other factors are determining bat numbers and species' occurrence. The two areas differed in altitude, tree species diversity and slope gradient, all of which could affect the numbers and species of bats found in each area. The data does seem to support a link between tree species diversity and bat diversity.

In addition to not having collected enough data whilst out in Guyana, the data collection was not set up with this hypothesis in mind. The main aim of Operation Wallacea is to collect data for conservation purposes - to record how individuals and populations of animal and plant species across the Guyana Shield are surviving and changing from year to year. In order to obtain data suited to this hypothesis, at least one more site (and preferably many more) would have to have been visited, collecting forestry and bat data in order to confirm a correlation.

Problems also occurred with the method of capture. Mist nets need to be very fine so that bats do not detect them. As a result, they are likely to fly straight into the nets. But, because of this, the nets are also very prone to tearing if snagged or bitten. Therefore, holes would often be left in the nets if a stick or insect were removed from the nets without enough care or, more frequently, if a bat chewed their way out. This not only allows for the captured bats to escape without being recorded, but also for other bats to fly through the holes which had been made. Although both sets of data were recorded at similar times of year (both at the end of the rainy season), they were a week apart. Ideally, the data would have been collected during the same week in both locations to minimise the num- ber of uncontrolled variables. Aiming to minimise the number of variables in data collection, or to record any discrepancies between the two sites, humidity, air temperature and wind speed, for example, all could have been recorded.

As has been seen above, to make any conclusions as to the effect that understorey foliage density would have on bat populations in these two areas it turns out that at least one further data set (and preferably more) is needed to test reliably for a negative or positive correlation between the two. This would allow a Spearman's Rank test then to be carried out but, as it is, a connection between the forestry and bat data is difficult to make. It can be seen where possible trends may arise, like with bat and tree species diversity, but without more data it cannot be certain although other authors have suggested that there is indeed a correlation. ${ }^{9}$

To get a better idea of the entire bat assemblage of each 1ocation, ideally taller nets, and a method of extracting bats from higher up in those nets, would have been used. This would provide data not only on the low flying, smaller, understorey feeders, but also the often-larger canopy feeders that tend to be found flying higher than the nets used. The collection was of data on only a fraction of the bats known to be present in the rainforests across Guyana.

If nets were checked more frequently, the likelihood of bats having time to chew their way out of the net would be smaller and therefore fewer holes would be made and so fewer bats missed.

Carrying out this project has made evident that it would be interesting to look further into the relationship between tree diversity and bat diversity. This study has shown that there may well be a connection and it would make sense for there to be correlation. It would be particularly interesting to look more closely at individual species preferences, like that possibly shown by Artibeus planirostris. Additionally, investigating the effect of sustainable logging on bat populations in surrounding areas could be very informative. One of the sites in the Iwokrama reserve, that unfortunately was not part of this data collection, is an area involved in sustainable logging. The effect of loss of potential food sources and roosting sites could be huge on the bat populations and since bats are such good indicators and maintainers of ecosystem health, on biodiversity generally; they distribute seeds and keep insect numbers down but are highly susceptible to changes in their environment. ${ }^{11}$

\section{- Methods}

Data was collected over a two-week period in the first half of July 2019, towards the end of the Guyanan rainy season. At this time of year, the temperature ranges from c. $30^{\circ} \mathrm{C}$ to low 20s at night, with high daytime humidity levels (fairly standard for this time of year). Rainfall was sporadic and heavy, often during netting hours in the evening, frequently accompanied by thunderstorms.

\section{Study sites:}

a) Turtle Mountain ('Turtle'):

The mountain has an elevation of $164 \mathrm{~m}$ surrounded by a flat region of forest. The bat net site was slightly above the base of the mountain, on a slight slope, above the river. It was further from water than the site at Rock Landing, but 
nearer to the Essequibo river. The Essequibo is c.500m wide at the nearest point to the net site and may have deterred frequent movement of many bats over such an exposed distance, perhaps slightly isolating bat populations from those on the opposite bank. The nets were c. $2 \mathrm{~km}$ from the main river and c. $20 \mathrm{~m}$ higher than it.

b) Rock Landing ('Rock'):

These nets were near water level (c. $3 \mathrm{~m}$ above) on a relatively flat area compared to the Turtle Mountain site. The nets were set up close to a small river, which would be easy for bats to traverse and may also offer a good food source in the form of insects and larvae, particularly for trawler feeder bats such as Noctilio albiventris. ${ }^{12}$

\section{Bat Data Collection:}

A series of mist nets were set up to trap the bats and the relevant information (as described later) was recorded between each netting period before setting them free.

Nets were set up as follows:

"Mist nets" are made of very fine black nylon c. $2 \mathrm{~cm}$ mesh. They have 4 horizontal furling strings; Figure $1 .^{13}$

One block of 18 "mist nets", in each location, were set up in pairs at right angles to form ' $L$ ' shapes in a $3 \times 3$ grid as shown in Figure 2. Nets were set up in this way as bats are known to zigzag in flight and so there was a higher chance of catching them in this layout than had the nets been in straight lines.

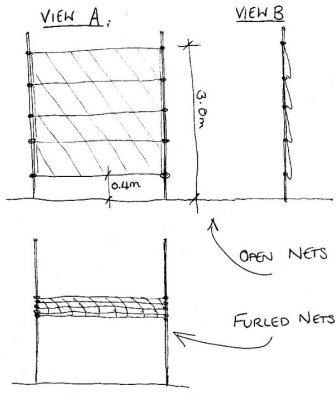

Figure 1: Mist net appearance.

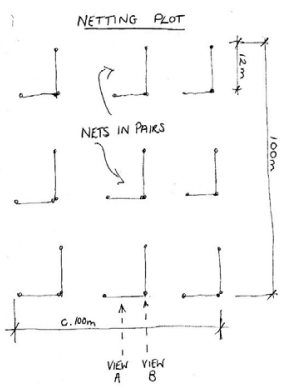

Figure 2: Mist net layout.
Each net was $2.6 \mathrm{~m}$ high $\mathrm{x} 12 \mathrm{~m}$ wide and c. $0.4 \mathrm{~m}$ above ground level, reaching to $3 \mathrm{~m}$ above ground level when open. Nets were suspended on poles secured to trees (see Figure 1). The grid of nets was located roughly in the centre of the area in which forestry measurements were taken and they spanned one of the forestry plots. The gap between the bottom of the net and the ground was to ensure that no small animals, foraging along the floor got ensnared in or ripped the nets. Net heights any higher than $3 \mathrm{~m}$ would have been difficult to extract bats from. The nets, split into four shelves, were slightly slack to prevent bats from bouncing off on contact or tearing straight through.

\section{Trapping times:}

Nets were left furled between closing and reopening the next night. They were opened at 17:30, shortly before dusk, and checked at 1.5-hour intervals until 23:30 when they were furled, c. 6 hours after opening. On opening, nets were checked for insects or debris and these were removed as anything of this nature could be detected by the bats and avoided, causing them to avoid the nets altogether. Bats caught in the nets were removed, placed in individual bags which were securely knotted and held by the string to minimise physical contact with the bat. These bats were carried back to camp a few minutes away. The nets stayed open until c.23:30 unless closed due to heavy rainfall as bats tend not to fly in bad weather. Any holes made by bats were mended to prevent others flying through.

\section{Bat release:}

Bats were released from camp. As the nets were quite close to camp and given the distances bats fly and their ability to navigate so effectively, it was not a problem to release them a short distance away from where they had been found. Subadults found in the nets alongside an adult of the same species were released together, on the grounds that they may have been parent and offspring. Any bats appearing to have sustained injury from being in the net (predation, exhaustion etc.) were given a small volume of sugar water in an attempt to give them energy to return to their roosts and heal.

\section{Data recording:}

Weight of bat was recorded (weight of empty bag subtracted from weight of bag with bat). Forearm length $(\mathrm{mm})$ was measured; the bat forearm is homologous to our own. Sex of the bat was also recorded, along with the age; adult or sub-adult (age is determined from examination of the bony protrusions on the front of the bat's forearms. Juveniles have smooth joints until they fully fuse, becoming more uneven and knobbly and recognisably adult).

Bats were then checked for recapture marks. If a bat was a new capture, a small wing punch was made in the bottom of the left wing membrane, between blood vessels. This does not endanger the bat as they heal over relatively fast and only leave a residual mark. As a natural part of life, bats receive multiple tears and rips in their wings, from predation and collisions, all of which heal over leaving a scar. If a bat had a mark from a previous wing punch, it was recorded as a recapture (see Table 1). The teeth were examined, and bats were then photographed (whole body, head and teeth). Dichotomous keys $^{10,14}$ were then used to determine its species (see Tables 2 and 3 ).

\section{Forestry Data Collection:}

Data was collected over an area of c. $3 \mathrm{~km} \times 3 \mathrm{~km}$ at each of Turtle Mountain and Rock Landing; data were taken from 11 plots at Turtle Mountain and 12 at Rock Landing. The $20 \mathrm{~m}$ x $20 \mathrm{~m}$ plots were roughly equally distributed across each site.

Five types of data were recorded in each plot, two of which are used in this paper.

Number of each species of tree was recorded (see Table 4) - data used for this study. Understorey foliage density was estimated in this study using 'touchpole' measurements as a proxy for foliage density. Poles were $3 \mathrm{~m}$ high (matching mist net heights). Measurements were taken at $1 \mathrm{~m}$ horizontal intervals along one East-West transect of the plot and one North-South transect. i.e. 2 × 20 measurements across the plot, 40 in total (please refer to Figure 3) - data used for this study.

The following data were not used in this study but could be used, for example, when investigating the effect of density of canopy foliage on the higher-flying bat species. The 
diameter at Breast Height (DBH) of trees was recorded: trees with diameter $>10 \mathrm{~cm}$ were measured. Taken together with approximate tree height, this data allows for a potential estimate of timber density/volume in each plot. Canopy density was then measured: a 'densiometer' was used to measure relative density of upper canopy in each plot, with 5 readings taken per plot and averaged. The points of light penetrating the canopy and seen on the densiometer were used as a proxy for foliage density. (The Spherical Crown Densiometer is a: reflective, shallow convex dome of c. $70 \mathrm{~mm}$ diameter marked with c.5mm grid. Points of light on grid intersections are counted and recorded whilst holding densiometer steady.) Five readings of leaf litter depth a were taken per plot using graduated stick. Results were averaged. This data also has not been used for this study.

Touchpole measurements taken along dotted axes

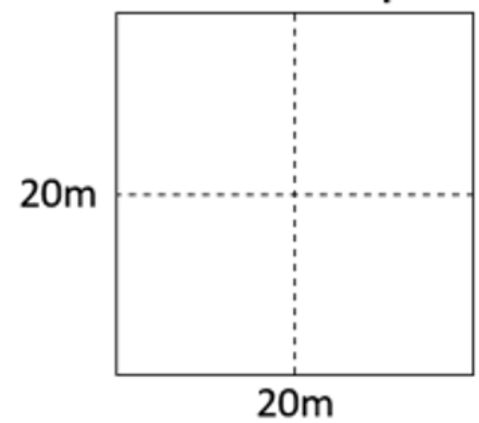

Figure 3: Touchpole transect.

At each of the 40 points, the number of vegetation touches on each pole was recorded (graduations not used for this study). In this study, a simple aggregate of total pole touches on all 40 poles was taken as an estimate of relative understorey density (see Table 5).

\section{Data Analysis:}

i. Bat Data:

The species data collected has been analysed using both the Shannon-Weaver and Simpson's indices to establish which of the two sites, Turtle Mountain or Rock Landing, have a higher diversity of bat species, as outlined later on.

\section{a) Shannon-Weaver Index of Diversity:}

Accounts for how 'evenly the total number of individuals in a sample is apportioned between each species. ${ }^{15}$

It does not take into account how many species are present, but how even the numbers of each species are.

It usually ranges from c.1-3.5, but can only be used to compare like with like as it gives relative values.

Where:

$$
H=-\sum^{s} p_{i} \ln p_{i}
$$

$\mathrm{H}=$ diversity

$\mathrm{p}_{\mathrm{i}}=$ proportion of a particular species.

$$
\begin{gathered}
H=-\left[\left(\frac{2}{166}\right) \times \ln \frac{2}{166}+\frac{8}{166} \times \ln \frac{8}{166}+\frac{2}{166} \times \ln \frac{2}{166}+\frac{72}{166} \times \ln \frac{72}{166} \ldots\right. \\
+\frac{1}{166} \times \ln \frac{1}{166}
\end{gathered}
$$

$=1.465$

\section{b) Simpson's Index of Diversity :}

Measures species "evenness" (no. of individuals of each species) and "richness" (no. of different species).

This differs from Shannon-Weaver; a location could have only four species, but if those species are evenly represented, it would have a high diversity. With Simpson's, a high diversity comes from evenness but also the number of different species. Fewer species and/or less even distribution of those species mean lower diversity.

$$
D=1-\frac{\sum n(n-1)}{\sum N(N-1)}
$$

Where:

$\mathrm{D}=$ diversity

$\mathrm{n}=$ no. of individuals of one species

$\mathrm{N}=$ no. of individuals of all species

e.g.

$$
D=1-\frac{2(2-1)+8(8-1)+2(2-1)+72(72-1) \ldots 1(1-1)}{166(166-1)}=0.60
$$

\section{Contingency Table and Chi-squared test :}

A Chi-squared test was used to compare the bat species ratios between the two locations and therefore to indicate whether bat species are dependent on their location.

A contingency table is used to work out the expected values for the chi-squared test (see Table 5). For the contingency table, only four species of bat were used. More could not be used, as their numbers were too few and would have led to expected values of below 5 which would have made the results of following calculations inaccurate and unreliable.

The species used are shown in Table 5.

The Chi-squared test compares observed and expected values (bat numbers). Expected bat numbers are calculated using a null hypothesis for the contingency table that assumes that ratios of each bat species are the same across both locations.

H0: bat species are independent of their location (therefore we would expect the same ratios of each bat species at both locations)

H1: bat species not independent of their location (ratios would be different between locations)

The expected values were worked out from the observed values:

$$
E=\frac{[\text { row total }] \mathrm{x}[\text { column total }]}{[\text { total number of bats }]}
$$

\section{e.g. A. planirostris}

$$
E=\frac{92 \times 95}{156}=56.024
$$

Table 7: Contingency Table.

\begin{tabular}{|l|c|c|c|c|c|}
\hline \multirow{2}{*}{ Species } & \multicolumn{2}{|c|}{ TOTAL Observed } & $\begin{array}{c}\text { Row } \\
\text { total }\end{array}$ & \multicolumn{2}{c|}{ TOTAL Expected } \\
\cline { 2 - 5 } & Turtle & Rock & & Turtle & Rock \\
\hline Artibeus obscurus & 2 & 17 & $\mathbf{1 9}$ & 11.571 & 7.429 \\
Artibeus planirostris & 72 & 20 & $\mathbf{9 2}$ & 56.024 & 35.974 \\
Carollia perspicillata & 13 & 18 & $\mathbf{3 1}$ & 18.878 & 12.122 \\
Pteronotus parnellii & 8 & 6 & $\mathbf{1 4}$ & 8.526 & 5.474 \\
\cline { 1 - 4 } Column total & $\mathbf{9 5}$ & $\mathbf{6 1}$ & $\mathbf{1 5 6}$ & & \\
\hline
\end{tabular}

Using the calculated expected values, a Chi-squared test can be carried out. 


$$
\chi^{2}=\sum \frac{(O-E)^{2}}{E}
$$

Where:

$\mathrm{O}=$ observed values

$E=$ expected values

e.g. $\chi^{2}=\frac{(2-11.571)^{2}}{11.571}+\frac{(72-56.024)^{2}}{56.024} \ldots=14.334$

Turtle Mountain:
$\chi^{2}=14.334$
Rock Landing:
$\chi^{2}=22.325$

Degrees of freedom $=(\mathrm{n}-1)(\mathrm{m}-1)$

$=(4-1)(2-1)=3$

ii. Forestry Data:

Forestry data has been analysed using:

1) the Shannon-Weaver test for diversity in the tree populations for each site

2) the Mann-Whitney $U$ test to find out if there is a statistically significant difference between the understorey density of each location, using the touch pole data as a proxy for that density.

\section{a) Shannon-Weaver:}

$$
H=-\sum^{s} p_{i} \ln p_{i}
$$

\section{b) Mann-Whitney UTest:}

This test determines whether the medians of the two sets of data are significantly different.

$$
\begin{aligned}
& U_{1}=n_{1} \times n_{2}+0.5 n_{2}\left(n_{2}+1\right)-\sum R_{2} \\
& U_{2}=n_{1} \times n_{2}+0.5 n_{1}\left(n_{1}+1\right)-\sum R_{1}
\end{aligned}
$$

Where:

$\mathrm{n}_{1}=$ sample size of first set of data

$\mathrm{n}_{2}=$ sample size of second set of data

$\sum R_{1}=$ sum of ranks of first set of data

$\sum R_{2}=$ sum of ranks of second set of data

Touchpole data from both Turtle Mountain and Rock Landing is combined and ranked from smallest to largest. The sum of each location's ranks is then put into the relevant equation along with the sample size of the set.

\section{Acknowledgements}

The author is grateful to all members of Operation Wallacea with whom she was lucky enough to spend a fascinating and informative two weeks in the Guyana Shield and in particular Iona Cunningham-Eurich and Johnny Wilson with whom bat and forestry data were gathered on site and also to Scott Sveiven and Dr. Burton Lim for generously sharing the data collected during the time the author was in Guyana. Thanks also to Dr. Richard Case and Mr Jerome Armstrong for their guidance on the writing of this study.

\section{References}

1. Bat Trust. Types of bats - About Bats - Bat Conservation Trust. https://www.bats.org.uk/about-bats/what-are-bats (accessed Sep 11, 2020).

2. Razing the land to feed massive timber hunger. https://wwf.panda. org/knowledge_hub/where_we_work/amazon/amazon_threats/ other_threats/logging_amazon/ (accessed Sep 11, 2020).
3. Law B., Park K.J., Lacki M.J. Insectivorous Bats and Silviculture: Balancing Timber Production and Bat Conservation. In Bats in the Anthropocene: Conservation of Bats in a Changing World, Voigt C., Kingston T., Eds.; Springer: Cham, CH, 2016.

4. Lim, B.; Engstrom, M. Mammals Of Iwokrama Forest. Proc. Acad. Nat. Sci. Philadelphia 2005, 154, 71-108.

5. The Essential Guiana Shield-Guyana Chronicle. https:/guyanachronicle.com/2018/11/28/the-essential-guianashield/\#: :text=The\%20area\%20is\%20the\%20only,and\%20it\%20 must\%20be\%20protected (accessed Sep 11, 2020).

6. Operation Wallacea | Conservation Research Expeditions https:// www.opwall.com/ (accessed Sep 11, 2020).

7. Denzinger, A.; Schnitzler, H. Bat Guilds, A Concept To Classify The Highly Diverse Foraging And Echolocation Behaviors Of Microchiropteran Bats. Frontiers in Physiology 2013, 4.

8. Altringham, J. Bats: From Evolution To Conservation; 2nd ed.; Oxford University Press: New York, 2011.

9. Caras, T.; Korine, C. Effect Of Vegetation Density On The Use Of Trails By Bats In A Secondary Tropical Rain Forest. Journal of Tropical Ecology 2009, 25, 97-101.

10.Lim, B.; Engstrom, M. Species Diversity Of Bats (Mammalia: Chiroptera) In Iwokrama Forest, Guyana, And The Guianan Subregion: Implications For Conservation. Biodiversity and Conservation 2001, 10, 613-657.

11.Medellín, R.; Equihua, M.; Amin, M. Bat Diversity And Abundance As Indicators Of Disturbance In Neotropical Rainforests. Conservation Biology 2000, 14, 1666-1675.

12.Lundrigan, B.; Kamarainen, A. Noctilio albiventris (lesser bulldog bat). https://animaldiversity.org/accounts/Noctilio_ albiventris/ (accessed Sep 11, 2020).

13.Gilroy,D.; Sveiven,S.; O'Shea, D.; Lim, D.; Hallett,M.; Fitzpatrick, D.; Pierre, M.; Bonat, S. Monitoring Biodiversity By Operation Wallacea In The Iwokrama And Surama Forests, Guyana; 2015.

14.Lopez-Baucells, A.; Rocha, R.; Bobrowiec, P.; Bernard, E.; Palmeirim, J.; Meyer, C. Field Guide to the Bats of the Amazon; 1st ed.; INPA, 2016.

15.Fowler, J.; Cohen, L.; Jarvis, P. Practical Statistics for Field Biology; 2nd ed.; Wiley: Hoboken, 2013.

\section{Author}

The author studied at Shrewsbury School and is going on to Oxford University to study Biological Sciences. This paper was inspired by a visit to Guyana over a period of two weeks during which field work allowed for data collection. 